\section{A Rare Complication of a Ventriculoperitoneal Shunt Resolved by Colonoscopy}

In addition to the two most frequent complications of obstruction and infection, ventriculoperitoneal (VP) shunts have been associated with a pseudocyst, mesenteric pseudotumor, metastasis of cerebral tumors via the shunt, and protrusion of the distal catheter through the scrotum or vagina $[1,2]$. Bowel perforation, especially of the colon, has been previously described in about 30 cases, usually in children [2].

A 33-year-old man underwent the insertion of a VP shunt for traumatic hydrocephalus. After 6 months, the protrusion of a strange structure through the anus during defecation was noted. Colonoscopic examination revealed that a part of the distal VP shunt had perforated the colon about $25 \mathrm{~cm}$ from the anus (Figure 1). The distal part was grasped and pulled straight with a "crocodile" clamp while the tube was cut and ligated upon its proximal abdominal entry site through a small incision at the right hypochondrium, after which the residual tube was removed through the anus. The patient recovered without complications, and at follow-up colonoscopic examination 10 days later the rectal wound had healed completely.

Perforation of an intra-abdominal hollow organ is a rare complication of a VP shunt and is associated with a $15 \%$ mortality [ 1 , 2]. A long-lasting adhesion of the catheter to the bowel may have led to its erosion, augmented by the stiff and sharp tip of the distal catheter [1,3].

In the management of rectal perforation caused by a VP shunt, three options have been suggested: total removal of the shunt, conservative management with intravenous antibiotics, and external ventriculostomy until the cerebrospinal fluid (CSF) becomes sterile $[1,3,4]$.

In the case discussed here, management consisted of colonoscopy-assisted removal of the peritoneal part of the catheter combined with antibiotic treatment, with good results.

\section{E. Pikoulis ${ }^{1}$, N. Psallidas ${ }^{2}$,}

P. Daskalakis ${ }^{1}$, K. Kouzelis ${ }^{3}$,

A. Leppäniemi ${ }^{4}$, P. Tsatsoulis ${ }^{1}$

1 2nd Department of Surgery,

General Hospital “Asclepeion” Voulas, Athens, Greece

2 Endoscopic Unit,

General Hospital “Asclepeion” Voulas, Athens, Greece

${ }^{3}$ Department of Neurosurgery,

General Hospital “Asclepeion” Voulas, Athens, Greece

${ }^{4}$ Department of Surgery, Helsinki University, Finland

\section{References}

${ }^{1}$ Digray NC, Thappa DR, Arora M et al. Silent bowel perforation and transanal prolapse of a ventriculoperitoneal shunt. Pediatr Surg Int 2000; 16: 94 - 95

${ }^{2}$ Ashpole R, Boulton R, Holmes AE. A case of asymptomatic passage per-rectum of a fractured redundant peritoneal catheter from a ventriculo-peritoneal shunt. Eur J Pediatr Surg 1995; 5: 280-281

${ }^{3}$ Jamjoom AB, Rawlinson JN, Kirkpatrick JN. Passage of tube per rectum: an unusual complication of a ventriculoperitoneal shunt. Br J Clin Pract 1990; 44: 525-526

${ }^{4}$ Schulhof LA, Worth RM, Kalsbeck JE. Bowel perforation due to peritoneal shunt. A report of seven cases and a review of the literature. Surg Neurol 1975; 3: $265-269$

\section{Corresponding Author}

\section{E. Pikoulis, M.D.}

2nd Department of Surgery

General Hospital "Asclepeion” Voulas

Aggelidou 5 Str.

Paleo Faliro, 17561

Athens

Greece

Fax: + 30-10-8959254

E-mail: Pikoulis@hellasnet.gr

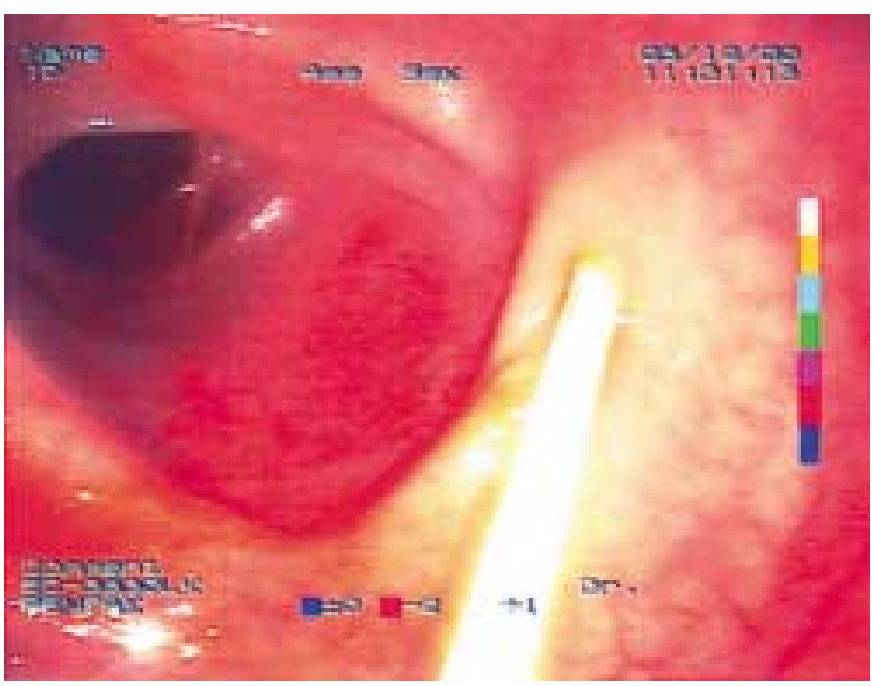

Figure 1 Part of the distal tube of the ventriculoperitoneal (VP) shunt had perforated the colon. 